disease seems to have been exterminated there, probably on account of isolation and acquired immunity. At the present time the natives of the island are a hardy race, and show no trace of the scourge which prevailed amongst their ancestors, in spite of the fact that in winter their diet consists largely of dried, partially cured, and imperfectly cooked fish, a diet which was once believed to be responsible for the propagation of leprosy.

The experience in Papa Stour cannot but suggest that an island is the ideal site for a leper colony, and should it be found necessary to adopt measures of segregation here it might be possible to find some such island where a colony could be established.

The contact cases here recorded show the danger of belittling the contagiosity of the disease in this country, and of gainsaying the risk connected with intimate association with lepers; it may not be amiss to quote the resolutions of the second Leprosy Congress at Bergen in 1909namely:

(1) "That leprosy is a disease that is contagious from man to man, whatever may be the method by which this contagion is effected."

(2) "That every country, in whatever latitude it is situated, is within the range of possible infection by leprosy, and may, therefore, usefully undertake measures to protect itself."

By means of a modified segregation, which was introduced in Norway in 1885, the number of cases was reduced in twenty years by about 50 per cent., and similar results have followed methods of isolation in Iceland and other countries. It does not seem inopportune at the moment to reconsider the advisability of putting our own house more in order, lest further cases should occur.

\section{A CASE OF MYASTHENIA GRAVIS. BY}

\section{A. H. DOUTHWAITE, M.D., M.R.C.P.LoNd.,} WORTHING.

Thrs case, I think, merits publication because the disease is comparatively rare, and the case also presents certain uncommon features.

A man, aged 57, sought my advice in March, 1924, on account of choking attacks occurring towards the end of meals. He had one healthy child. His mother had died of diabetes and his father of rectal carcinoma. Apart from scarlet fever at the age of 8 his health had always been good.

\section{History of Illiness.}

In 1913 he noticed that on tapping the extensor surface of either forearm or thigh the underlying muscle rose up in a wheal. His eyes happened to be examined at this time on account of errors of refraction; no ophthalmoplegia was then present. In 1914 he had a transient attack of abdominal pain and nausea accompanied by bilateral ptosis. This was attributed to his having eaten bad fish. Later in this year the muscles of the thigh and gluteal regions felt stiff and an unusual effort was required to rise from a stooping posture. Transitory diplopia also occurred about this time.

From then until May, 1923, the patient felt well, but the irritability of his muscles persisted. Since 1923 he had harl frequent attacks of diplopia, which at first lasted from one to three days. From January, 1924, the condition became permanent, but was always less noticeable in the early morning. In March he noticed weakness of the jaw towards the end of a meal, and found that if he assisted it with his hand he was unable to close his mouth for half an hour afterwards. Being informed that he was suffering from a nervous breakdown associated with high blood pressure, he was advised to go to the seaside. His condition here became steadily worse, and marked ptosis in both eves developed. For this he wore glasses, but found that the more he attempted to keep his eyes open the more complete was their closure. On the evening of March 27th fluid suddenly regurgitated through his nose whilst he was drinking, and a choking attack ensued.
C'ondition on Examination.

When giving me the above history a remarkable change passed over him. Whereas at the commencement of the recital his voice was clear and strong, yet, as he talked, a nasal twang developed to a pronounced degree. The forehead, previously wrinkled, became smooth, and bilateral ptosis developed coincidently. From time to time he stopped to support his jaw, then with a further effort struggled to the completion of the sentence. The main points discovered on examination were :

1. Pronounced hippus when a light was thrown on the eyc.

2. Normal reflexes and sensations.

3. Blood pressure 162 and 105 .

4. All except the muscular system normal. A skiagram of the chest revealed no suggestion of thymic shadow.

5. Muscular system: Weak right external rectus. Ptosis, which became more pronounced if the patient made a sustained effor to look upwards. Inability to roll $r$ 's when speaking, and to whistle. The masseters were rapidly fatigued by faradism, recovered after rest, and were again fatigued after the passage of the current for one minute forty seconds. They were then capable of weak voluntary movement and of contraction to the galvanic current. The " nasal smile" or " myasthenic snarl" was exhibited in an attempt to smile after conversation. The upper lip was drawn upwards in the effort, movement at the corners of the mouth being absent. Movement of the soft palate was defective, with slight deviation to the right. No weakness of the limb muscles was demonstrable, but they all showed the remarkablo excitability to direct mechanical stimulation already referred to. This was chiefly marked in the extensors, a tap of the finger producing a wheal-like swelling of the muscle, which persisted in one case for three minutes. The reaction was precisely such as one finds in Thomsen's disease, of which, however, there was 1:0 further sign.

\section{Choling Attack.}

On the evening of April 19th I received an urgent summons as the patient was choking. I found him in a prostrate condition, filled with fear of impending death. The respiration was both stertorous and stridulous, the soft palate flapping to and fro with each breath. At the time it was impossible to examine the condition of the vocal cords, but on the following day a definite weakness of abduction could be detected. Apparently, previous to this attack, he had been talking more than was his wont, but the actual onset was precipitated by his taking some bismuth. Feeling the powder cling to the back of his throat, he made violent but largely ineffectual efforts to clear it, thus rapidly exhausting the pharyngeal muscles. Rhonci and râles could be heard over both lungs at this time, and the patient complained of inability to "cleal his chest." The condition improved during the following day, and in thirty-six hours he suddenly coughed up ten ounces of viscid mucoid sputum, expressing himself mu:h relieved thereby.

\section{Treatment.}

Treatment was mainly directed towards securing as complete rest as possible for the affected muscles. Visitors were forbidden. All food was minced so as to reduce mastication to a minimum. Both eyes were covered by shades for the greater part of the day. The masseter's and larynx were daily subjected to diathermy, which appeared to produce a definite amelioration of the condition. Strychnine was administered by the mouth.

Gradual improvement followed, so that when last seen in June there had been no further choking attacks; nasal intonation of the voice was very slight; diplopia was often absent during the greater part of the day. The patient was thus able to return home and resume light work.

Presumably the ultimate prognosis is thoroughly bad.

The main point of interest in this case is to be found in the muscular excitability to mechanical stimulation. Those muscles which were clearly affected by the myasthenia -for example, the masseters-failed to react abnormally to tapping. So far as I know this condition has not heen previously described in myasthenia gravis, and I should be interested to hear opinions as to whether its occurrence here should perhaps be regarded rather as a coincidence than an unusual manifestation of the disease. 